\title{
Not Known if Bone Marrow Aspirate Immunophenotyping and Cytochemistry Were Performed
}

National Cancer Institute

\section{Source}

National Cancer Institute. Not Known if Bone Marrow Aspirate Immunophenotyping and

Cytochemistry Were Performed. NCI Thesaurus. Code C160432.

An indication that it is not known if immunophenotyping and cytochemistry were

performed on bone marrow aspirates during the study. 